\title{
La République des Lettres au féminin et le différentialisme latino-américain
}

\author{
Thérèse Courau, Université de Toulouse
}

Les années quatre-vingt constituent un tournant dans la construction du positionnement des femmes dans l'espace littéraire international. Si la mal nommée «République des Lettres » s'est structurée en reprenant à son compte le discours masculiniste, les discours artistiques pris dans un interdiscours qui depuis les années soixante-dix a été modifié par la consolidation du discours féministe- se posent dès lors comme un espace de reconceptualisation des identités sexuées et surtout, du rapport entre création et configuration symboliques du masculin et du féminin en littérature. La circulation des discours féministes va engendrer une internationalisation précoce des stratégies de positionnement féministe dans le champ des Lettres -dont la revendication de l'écriture féminine est le pivot- notamment dans l'aire culturelle des Amériques.

Cependant la réalité que recouvre la notion d' "écriture féminine transnationale », même circonscrite à l'aire culturelle des Amériques, n'est pas sans poser problème et demande une approche intersectionnelle de deux notions problématiques en elles-mêmes. Se pose en premier lieu la question de la revendication de l'existence de l'écriture dite féminine qui a suscité nombre de débats et divisé le féminisme international. Alors que les constructivistes soulignent le danger du maintien du discours des femmes dans le cadre limitatif du féminin essentialisé avec lequel elle fraye, les tenantes de la politique de la différence ont reproché quant à elles aux partisanes de la confusion des genres l'utopisme d'une position désexuée intenable. À cette tension se surimpose par ailleurs la problématique de la circulation internationale des discours féministes sur la base d'échanges inégaux dans une aire culturelle informée par les rapports Nord-Sud. Dans les espaces littéraires latino-américains, la structuration hiérarchique genrée vient en effet croiser la position périphérique des champs nationaux par rapport aux puissances littéraires centrales.

Nous proposons dans cet article d'interroger la manière dont cette double tension a historiquement informé les discours des autrices et critiques latino-américaines dont la position d'énonciation dans la République des Lettres relève d'une marginalisation multiple, issue de facteurs croisés : par rapport à la tradition littéraire masculiniste, en tant que femmes, mais également aux centres en tant que féministes des périphéries. Nous postulerons en effet que l'analyse du rapport des discours féministes périphériques aux centres -tant au niveau des filiations que des polémiques qu'il génère- met en scène les enjeux complexes de la convocation du féminin dans le redéploiement des rapports entre identités sexuées et création auquel procèdent les critiques littéraires féministes. Et ce, dans un contexte de subalternité assumée qui déplace la ligne de partage entre pourfendeuse et tenante de l'écriture féminine et exhibe le point aveugle ou peut-être l'impensé stratégique que masque cette catégorisation dichotomique.

\section{Préambule : Internationale féministe en littérature et hiérarchies énonciatives dans l'aire des Amériques}

Si dans les années quatre-vingt émerge une production critique nationale en Argentine, au Chili ou encore au Mexique, la critique littéraire féministe s'internationalise dès le début de la consolidation d'un champ d'étude sur la production des femmes en Amérique Latine. Ainsi, nombreuses sont les Nord-américaines qui se spécialisent sur la production du continent latino-américain et les critiques latino-américaines qui écrivent sur la production des femmes de leurs pays d'origine depuis les grandes universités étasuniennes. La diaspora intellectuelle 
latino-américaine aux États-Unis, même si elle est source de polémiques entre les Latinoaméricaines écrivant depuis l'Amérique Latine et celles qui se sont " exilées », empêche toute distinction simpliste entre critique nationale, régionale et internationale qui ne prendrait pas en compte ces phénomènes d'hybridations et de traductions culturelles.

L'exemple de la "Conférence des Femmes-écrivains des Amériques », tenue à l'Université d'Ottawa en mai 1978 est révélateur de ce processus. Cet important colloque, qui s'était donné pour objectif de porter au jour la spécificité féminine aussi bien des productions littéraires que de la critique des œuvres des femmes, a marqué un tournant dans l'histoire de la construction du positionnement des femmes dans l'aire culturelle des Amériques en réunissant les plus grandes autrices et critiques nord-américaines, canadiennes et sudaméricaines. Lorsqu'on considère, en outre, l'influence des théories françaises de Luce Irigaray, Hélène Cixous ou Julia Kristeva sur les conceptualisations de l'écriture féminine, développées lors de ce colloque interaméricain, on mesure la constitution d'une «internationale féministe » qui travaille à la construction d'une contre-mythologie en littérature qui se cristallise, à ses débuts, autour de la revendication du féminin en écriture et du rapport spécifique du corps au langage ${ }^{1}$.

À cette époque, la confrontation aux schèmes masculinistes de la création littéraire invite en effet la critique féministe internationale à, selon l'expression de Michelle Coquillat dans $L a$ poétique du mâle, «[re]mettre en équation sexualité et création ${ }^{2}{ }$. C'est à travers la prise en compte de ce nécessaire devoir de réponse à un sous-texte masculiniste, relativement homogène, qui construit une féminité mythique incompatible avec la création, que prend sens le différentialisme stratégique en tant que stratégie de négociation des écrivaines qui doivent réinvestir le rapport entre «différence des sexes » et autorité énonciative. La revendication de l'existence de l'écriture féminine, très en vogue dans les années quatre-vingt, s'inscrit alors au répertoire interaméricain des solutions littéraires qui cherchent à renverser l'ordre sexué du discours, jusque-là fondé sur l'antagonisme ontologique entre féminité et littérarité, et par rapport auquel les femmes, intervenant en tant qu'énonciatrices secondes dans le champ des Lettres, doivent se positionner.

La mise en évidence de ce processus d'internationalisation ne doit pas pour autant déboucher sur une vision déhiérarchisée d'une République des Lettres au féminin artificiellement unifiée qui reposerait sur une sorte de sororité littéraire de principe.

On pose en effet, encore aujourd'hui, le remaniement des rapports entre écriture et identités sexuées en Amérique Latine comme étant fortement influencé par les échanges avec les centres culturels nord-américains et la réappropriation des conceptualisations -forgées en leur sein- du processus de "venue à l'écriture » des femmes et de création d'une " voix propre ». Les critiques et autrices latino-américaines sont ainsi souvent considérées comme les « héritières » aproblématiques des «pionnières » des centres, dans un processus qui masque et naturalise dans un même mouvement la position marginale des écrivain-e-s latinoaméricain-e-s. Comme l'ont mis en évidence Nelly Richard ${ }^{3}$ ou encore Francine Masiello ${ }^{4}$, soulignant les rapports intersectionnels entre les enjeux historiques des rapports de genre et des rapports Nord-Sud, le centre nord-américain continue d'être par ailleurs envisagé comme le lieu de la théorisation quand la périphérie latino-américaine fournirait les études de cas. Si l'on abandonne cette conception linéaire et verticale de la circulation des théories féministes -

\footnotetext{
${ }^{1}$ Revue de l'Université d'Ottawa, vol. 50, nº 1, Janvier-Mars 1980.

${ }^{2}$ Michelle Coquillat, La poétique du mâle, Paris, Gallimard, 1982, p. 368.

${ }^{3}$ Nelly Richard, «Feminismo, experiencia y representación », Revista Iberoamericana, vol. LXII, n 176-177, Julio-Diciembre de 1996.

${ }^{4}$ Francine Masiello, El arte de la transición, Buenos Aires, Norma, 2001, p. 183.
} 
notamment du concept d'écriture féminine qui nous intéresse plus particulièrement ici- pour adopter le modèle du rhizome, on s'offre l'opportunité de problématiser la complexité de la géopolitique de l'écriture féminine transnationale qui exhibe les tensions à l'œuvre dans la mobilisation de la féminité en écriture et permet, peut-être, de poser autrement cette problématique.

\section{Captation et subversion des discours des centres par la périphérie latino-américaine}

Si l'on se place dans cette perspective, s'offre à l'observation un double phénomène de captation et de subversion des discours des centres nord-américains et européens par la périphérie latino-américaine qui porte au jour la complexité de la convocation de l'écriture féminine en tant que stratégie de positionnement dans le champ littéraire.

À partir des années quatre-vingt, la critique féministe latino-américaine va largement s'appuyer sur les discours théoriques des féministes dites des centres pour légitimer leurs prises de position. Les discours issus des women's studies fonctionnent alors comme un intertexte légitimant. Elaine Showalter avec A Literature of their $O w n^{5}$, Sandra Gilbert et Susan Gubar avec The Madwoman in the Attic ${ }^{6}$, ou encore les représentantes de ce que les nord-américaines construisent comme le French Feminism : Hélène Cixous, Luce Irigaray et surtout Julia Kristeva, deviennent les références principales de la critique latino-américaine dans son entreprise de promotion de l'écriture féminine.

Dans sa contribution au «Congrès International de littérature féminine latino-américaine » tenu en 1987 à Santiago du Chili, Adriana Méndez Rodenas illustre ce phénomène en s'inscrivant dans la filiation légitimante de Virginia Woolf et en convoquant des théoriciennes telles que Elaine Showalter ou Julia Kristeva, ou encore en renvoyant aux topiques de l'avantgarde féministe, notamment à travers les notions empruntées à Hélène Cixous de «corps textuel féminin » et de « sexte »

La paradoja de la letra femenina emerge en este vaivén entre la diferencia o escritura marcada, a un extremo, y la « neutralidad » o cancelación de contrarios al otro. Hacia el final de Un cuarto propio, Virginia Woolf alerta a la mujer del peligro de asumir la escritura exclusivamente desde su identidad sexual, y propone la alternativa de una androginia literaria, la imaginación creadora no-diferenciada que absorbe tanto a la mujer como al hombre. [...]. El neologismo « sexto » de Cixous nombraría a esa textualidad « diferente », nueva, ya sea consecuencia de autoría femenina o producto de otros proyectos escriturales emprendidos desde los márgenes del discurso « aceptado ». La huella de la mujer transcribiría una identidad textual propia, y a la vez desmontaría las falacias con que críticos y creadores denigran a la mujer en su papel de receptora y de productora de textos ${ }^{8}$.

On voit ici que la critique latino-américaine prend part au débat sur l'écriture féminine en présentant un positionnement complexe qui fait largement écho à la tension entre la convocation de la différence féminine comme indice identificatoire et le questionnement des différenciations qui traverse la critique féministe internationale. Lors de ce même colloque, l'inscription dans les polémiques qui agitent les women's studies se retrouve dans la contribution de Lucía Guerra Cunningham, «Silences, dissidences, hésitations: les problèmes théoriques de la nouvelle critique féministe ». La critique, après avoir passé en revue les

\footnotetext{
${ }^{5}$ Elaine Showalter, A Literature of their Own, London, Virago, 1977.

${ }^{6}$ Sandra M. Gilbert and Susan Gubar, The Madwoman in the Attic: The woman writer and the nineteenthcentury literary imagination, New Haven, Yale University, 1979-1984.

${ }^{7}$ Hélène Cixous, Le rire de la Méduse et autres ironies, Paris, Galilée, 1975-2010, p. 54.

${ }^{8}$ Adriana Méndez Rodenas, «Tradición y escritura femenina », Carmen Berenguer, Eugenia Brita, Diamela Eltit, Raquel Olea, Eliana Ortega y Nelly Richard (eds.), Escribir en los bordes. Congreso internacional de literatura femenina latinoamericana 1987, Santiago de Chile, Cuarto Propio, 1990, p. 63.
} 
apports de ce qu'elle nomme «l'école américaine» (Showalter, Gilbert et Gubar) et de «l'école française» (Irigaray, Cixous), propose une approche de «la spécificité de l'esthétique féminine ${ }^{9}$ » depuis la sémiotique kristévienne : «Es Julia Kristeva quien nos provee con un planteamiento teórico más sólido al partir del concepto de lo semiótico como modalidad pre-verbal y pre-simbólica conscientemente reprimida por el Logos ${ }^{10} \gg$.

La revendication différentialiste, qui empreigne pourtant largement les premières théorisations féministes en littérature dès le début du $\mathrm{XX}^{\mathrm{e}}$ siècle en Amérique Latine -à l'image des positions d'Alfonsina Storni- est ainsi largement soutenue par l'inscription dans la filiation des women's studies et du French feminism. Cette relative occultation des filiations historiques du féminisme latino-américain et ce déplacement d'héritage -de la tradition latino-américaine régionale au féminisme des centres- semblent répondre à un double enjeu stratégique dans la mesure où il permet aux critiques latino-américaines de s'inscrire dans la filiation d'un discours qui possède une certaine autorité tout en mettant à distance, autrement dit en n'assumant pas pleinement, la responsabilité énonciative du «paradoxe différentialiste ». On assiste ainsi à un processus de projection des contradictions historiques de la critique féministe sur une tradition exogène, de la même manière que les Etats-Unis projettent sur la France en construisant le French feminism ${ }^{11}$.

À ce processus de captation, se surimpose néanmoins un processus de questionnement acerbe. Si la critique latino-américaine s'inscrit dans la filiation légitimante de la critique nordaméricaine, elle va également s'employer à resignifier ses postulats en revendiquant une spécificité liée au contexte latino-américain. Et c'est dans le sillage du Black feminism et du féminisme chicano, qui se développent aux États-Unis à partir des années soixante-dix, que les théoriciennes latino-américaines vont paradoxalement chercher à se différencier des centres et problématiser à leur tour l'oppression multiple dont les femmes sont victimes en Amérique Latine. Influencées par le développement du féminisme post-colonialiste notamment théorisé par Bell Hooks et Gayatri Spivak ${ }^{12}$ - les critiques et autrices latinoaméricaines vont en effet questionner le féminisme des centres -qu'elles convoquent néanmoins pour se légitimer- en dénonçant la non-prise en compte en son sein de la spécificité de leur histoire coloniale et de l'expérience propre des femmes du TiersMonde dont l'oppression est déterminée par des rapports de domination multiples.

Les critiques latino-américaines vont tout d'abord mettre en évidence la non-adéquation des présupposés méthodologiques et idéologiques des théories féministes nord-américaines dans l'analyse de la production des autrices latino-américaines. Patricia Elena González, dans l'introduction aux actes du premier colloque sur la production littéraire des femmes en

\footnotetext{
${ }^{9}$ Lucía Guerra Cunningham, « Silencios, disidencias y claudicaciones: los problemas teóricos de la nueva crítica feminista », Carmen Berenguer, Eugenia Brita, Diamela Eltit, Raquel Olea, Eliana Ortega y Nelly Richard (eds.), Escribir en los bordes. Congreso internacional de literatura femenina latinoamericana 1987, op. cit., p. 25. [Nous traduisons].

${ }^{10}$ Ibid., p. 49. On retrouve cette revendication de la pensée kristévienne dans les deux principaux essais de la critique : Lucía Guerra Cunningham, La mujer fragmentada. Historia de un signo, La Habana, Casa de las Américas, 1994 et Lucía Guerra Cunningham, Mujer y escritura. Fundamentos teóricos de la crítica feminista, Santiago, Cuarto Propio, 2008.

${ }^{11}$ Comme le souligne Christine Delphy, le French feminism est le résultat d'une construction théorique nordaméricaine qui a promu des théoriciennes telles qu'Hélène Cixous, Julia Kristeva et Luce Irigaray comme représentantes du féminisme français, en dépit du fait qu'elles occupent une place secondaire sur la scène féministe de l'hexagone. (Christine Delphy, L'ennemi principal 2/ Penser le genre, Paris, Syllepse, 2001, p. 319$358)$.

${ }^{12}$ Voir, entre autres, Bell Hooks, Ain't I a Woman ? Black Women and Feminism, London, Pluto Press, 1981 et Gayatri Spivak, «Can the Subaltern Speak ? (1988), Patrick Williams y Laura Chrisman (Eds.), Colonial Discourse and Post-Colonial Theory. A Reader, Hertfordshire, Prentice Hall, 1993.
} 
Amérique Latine organisé en 1983 par le Amherst College, insiste ainsi sur la nécessité de construire une grille de lecture propre à l'écriture féminine en Amérique Latine en opérant un double mouvement de prise de distance vis-à-vis des schèmes patriarcaux et des schèmes de la critique féministe internationale :

Así como existe el peligro de utilizar las construcciones y referencias del poder masculino dominante, [...], existe también el peligro de la infiltración y colonización de las culturas dominantes. [...]. Mientras en las discusiones se señaló que algunas aproximaciones críticas a la literatura femenina empleaban la valorización de los cánones masculinos, también se demostró que otras aproximaciones, aunque no masculinas, tampoco articulaban la experiencia de la mujer latinoamericana. Los modelos teóricos femeninos de otras culturas, aplicados a los textos de escritoras latinoamericanas, tampoco lograban definir aquello de « la escritura femenina latinoamericana $»^{13}$.

Au-delà de la question de l'écriture féminine, c'est donc la définition de la spécificité de l'écriture féminine latino-américaine qui est en jeu et qui va déterminer de manière centrale l'inflexion du processus de remaniement des rapports entre création et identités sexuées en Amérique Latine.

Lors de ce colloque, dans une contribution qui a fait date, intitulée «La critique littéraire féministe et l'écrivaine en Amérique Latine», Sara Castro Klarén souligne également l'inefficacité théorique de l'appareillage conceptuel féministe nord-américain "importé », pour prendre en charge la «double négativité » ${ }^{14}$ qui caractérise la position d'énonciation des autrices dans les sociétés colonisées. Elle met ainsi en évidence qu'on ne pourrait établir de continuité entre, d'un côté, les écrivaines anglaises du XIX ${ }^{\mathrm{e}}$ siècle, auxquelles s'intéresse Elaine Showalter dans l'ouvrage de référence A Literature of their Own et, de l'autre, les représentantes de la littérature des femmes en Amérique Latine telles que Elena Poniatowska, Rosario Castellanos, Rosario Ferré, Sylvia Molloy ou encore Clarice Lispector ${ }^{15}$. La position d'énonciation spécifique des autrices latino-américaines déborderait ainsi, selon la critique, les cadres de conceptualisation proposés par la critique nord-américaine :

Las críticas [norteamericanas] definen el lugar de la escritura en términos de un espacio dominado por el padre creador. [...]. Hasta aquí estoy de acuerdo. Difiero de ellas en cuanto me parece que esta negación de la mujer por el sistema dominante no es única en la historia sino que tiene patrones análogos en la historia de las sociedades coloniales. La retórica de la opresión sexual tiene su paralelo en la retórica de la opresión racial o mejor dicho La Retórica de la Opresión que se ha practicado a través de la historia contra muchos y varios grupos $^{16}$.

La remise en cause des prétentions universalistes du féminisme hégémonique va déboucher sur un processus de politisation du positionnement féministe latino-américain en littérature qui cherche à articuler les revendications féministes, antiracistes et anti-impérialistes. Eliana Ortega ouvre ainsi le colloque de Santiago en surimposant au questionnement de la spécificité du discours des femmes celui de la spécificité du discours des autrices en Amérique Latine, qui nécessite une contextualisation en fonction des «coordonnées historico-idéologiques » propres au sous-continent latino-américain :

¿Es posible que el discurso feminista internacionalizado de Europa y E.E.U.U., en ocasiones con una visión del mundo a priori paternalista y colonialista, pretenda definir la realidad de Latinoamérica, en específico de la

\footnotetext{
${ }^{13}$ Patricia Elena González, «Introducción », Patricia Elena González y Eliana Ortega (ed.), La sartén por el mango, Río Piedras, Ediciones Huracán, 1985, p. 16-17.

${ }^{14}$ Sara Castro Klarén, «La crítica literaria feminista y la escritora en América Latina », Patricia Elena González y Eliana Ortega (ed.), La sartén por el mango, op. cit., p. 43. [Nous traduisons].

${ }^{15}$ Ibid., p. 32. Cette mise en garde contre l'ethnocentrisme de la critique nord-américaine et européenne sera développée par Sara Castro-Klarén dans l'introduction de l'ouvrage collectif Narrativa femenina en América Latina: Prácticas y perspectivas teóricas, Madrid/Frankfurt, Iberoamericana/Vervuert, 2003.

${ }^{16}$ Sara Castro-Klarén, « La crítica literaria feminista y la escritora en América Latina », art. cit., p. 40.
} 
mujer escritora, imponiéndole sus parámetros ideológicos y metodológicos foráneos ? [...] Ya que en los congresos de escritoras se parte a priori de la pregunta ¿en qué consiste la especificidad de la escritura femenina? ¿No debemos considerar dicha pregunta partiendo de las siguientes premisas? : [...] ¿Significa la escritura femenina sólo la invención de un nuevo lenguaje « a lo jouissance »? Más bien ¿no estaremos en presencia del establecimiento de un nuevo discurso [...] que se produce en una relación dialéctica constante, inserto en las coordenadas histórico-ideológicas de la realidad latinoamericana ${ }^{17}$ ?

Dans certains pays d'Amérique Latine, comme au Mexique, l'analyse des mécanismes entremêlés de la domination conduira critiques et autrices à mettre au premier plan la question du croisement entre la problématique des rapports de genre et de l'oppression raciale. Dans les pays du Cône Sud, à forte majorité blanche, l'accent est mis sur la situation de domination néocoloniale et la violence politique qui caractérisent les dictatures militaires des années quatre-vingt et le questionnement croisé entre l'oppression patriarcale et dictatoriale. Lors du colloque de 1988, «Bases culturelles et historiques pour la critique féministe hispanique et brésilienne ", Lucía Guerra Cunningham met ainsi en évidence dans son intervention ce déplacement «vers la politisation de l'écriture féminine ${ }^{18}$ », en analysant les différentes inflexions du positionnement féministe en littérature selon que la problématique du genre croise celle de la race, de la classe ou de la violence politique :

Las escritoras latinoamericanas contemporáneas han descubierto el enemigo, han tomado una posición política con respecto a un sistema masculino que en el Tercer Mundo se expresa de manera homóloga tanto en las relaciones hombre-mujer como en las estructuras de opresor-oprimido. [...]. Dentro de este contexto, la mirada del Otro en lo Otro ha resultado fuente prolífera para la inscripción de un contra-discurso. Los testimonios de Jesusa Palancares, Domitila Chúngara y Rigoberta Menchú ponen en evidencia la especificidad de una problemática femenina inserta en los espacios populares e indígenas marginalizados. [...]. Luisa Valenzuela, Marta Traba, Elvira Orphée y Ana Vásquez son algunas de las escritoras que representan la tortura no sólo como un testimonio de la represión política sino también con una clara conciencia feminista que la ubica en el contexto mayor de la violencia masculina ${ }^{19}$.

De la double entrée en polémique avec les topiques de la poétique du mâle et ceux de la version hégémonique de l'écriture féminine naît la notion d'écriture féminine latinoaméricaine. En opposition à l'écriture féminine des centres, taxée d'acontextuelle, d'apolitique, et d'individualiste, s'invente le différentialisme latino-américain en littérature qui promeut une écriture féminine politisée, ancrée dans la réalité historique et politique régionale et met en adéquation féminité et subversion.

\section{2. «Trafic de théories » en Amérique Latine et exhibition de l'impureté des stratégies féministes en littérature}

Ce qui semble fondamental dans ce processus de remaniement, c'est que le «trafic de théories ${ }^{20} \gg$ qui se joue dans la construction de l'écriture féminine latino-américaine ouvre un espace de resignification irrévérente, de production de savoir situé qui exhibe, en les déplaçant, les enjeux à l'œuvre dans les débats qui structurent l'épistémologie féministe dominante.

\footnotetext{
${ }^{17}$ Eliana Ortega, «Y después de todo aquí estamos », Carmen Berenguer, Eugenia Brita, Diamela Eltit, Raquel Olea, Eliana Ortega y Nelly Richard (eds.), Escribir en los bordes. Congreso internacional de literatura femenina latinoamericana 1987, op. cit., p. 23-24.

${ }^{18}$ Lucía Guerra Cunningham, «Las sombras de la escritura: hacia una teoría de la producción literaria de la mujer latinoamericana », Hernán Vidal (ed.), Cultural and Historical Grounding for Hispanic and LusoBrasilian Feminist Literary Criticism, Mineapolis, Institute for the Study of Ideologies and Literature, 1989, p. 155. [Nous traduisons].

${ }^{19}$ Ibid., p. 153-154.

${ }^{20}$ Concernant cette notion de «trafic de théories » en Amérique Latine, voir l'article de Claudia de Lima Costa : «Repensando el género : tráfico de teorías en las Américas », María Luisa Femenías (comp.), Perfiles del feminismo iberoamericanos, Buenos Aires, Catálogos, 2002.
} 
Dans les années quatre-vingt-dix, la diffusion de la pensée de Monique Wittig ${ }^{21}$, Teresa de Lauretis ou encore Judith Butler ${ }^{22}$, qui se fonde sur la critique du différentialisme pour proposer une réflexion qui se centre sur le questionnement des différenciations et pose les bases de la pensée queer, marquera également la critique littéraire féministe latinoaméricaine. Or, le processus de «politisation » du positionnement féministe en littérature aura des implications dans la manière propre dont les critiques latino-américaines vont bouleverser la ligne de partage entre «différentialisme » et «déconstructivisme» qui structure alors les débats des « centres ».

Lors du colloque «Bases culturelles et historiques pour la critique féministe hispanique et brésilienne ", l'intervention de Gabriela Mora qui, dans une contribution intitulée «Un dialogue entre féministes hispano-américaines », met en scène une table ronde fictive entre des critiques littéraires féministes latino-américaines, témoigne de cette dynamique. La question inaugurale posée par la critique concerne l'enjeu de la construction d'un discours critique littéraire féministe "par et pour » l'Amérique Latine. D'entrée de jeu, la spécificité latino-américaine est située au niveau de la nécessité de contextualisation du discours des femmes en lien avec la position périphérique du sous-continent ${ }^{23}$. Découle de ce postulat de départ une remise en cause de la pertinence des théories féministes nord-américaines aussi bien « déconstructivistes » que « différentialistes »:

G. : Teresa de Lauretis dice en su Feminist Studies/Critical Studies que del discurso feminista va emergiendo un concepto de identidad múltiple, cambiante, muchas veces contradictoria, hecha con « representaciones heterogéneas y heterónomas » de género, raza y clase. [...].

D. : Concuerdo contigo. Soy la primera en reconocer cómo la deconstrucción ha impulsado la práctica feminista por caminos más novedosos. Pero creo que debemos estar alerta al peligro de caer en la despolitización cuando se exageran o se malinterpretan ciertas nociones «posmodernistas ». [...]. Una cosa es rechazar las fijaciones esencialistas y metafísicas, pero otra es negar toda realidad ${ }^{24}$.

À la fois l'adoption et la remise en cause des théories de Teresa de Lauretis et, par voie de conséquence, du positionnement queer fondé sur l'anti-essentialisme et la prolifération des identités de genre -il en ira de même avec Butler-s'appuient ainsi sur la mise en évidence du danger de « dépolitisation » qui serait consubstantiel au post-modernisme. C'est parallèlement le même argument de la nécessité de prise en compte de la dimension politique du discours des autrices qui va servir le questionnement des théories d'Hélène Cixous ou de Julia Kristeva et, plus largement, du French feminism dans ses liens avec la psychanalyse, constituant par làmême la pierre angulaire du positionnement spécifique d'un secteur majoritaire de la critique latino-américaine :

H. : A mí me gustó lo que dijo ayer L en su trabajo, sobre el «pensar materno » que algunas norteamericanas propulsan.

J. : No sé cómo se explican entonces los casos de mujeres que llamaron a la guerra como en Chile en el 73, por ejemplo. [...].

\footnotetext{
${ }^{21}$ L'ensemble des essais regroupés en 1992 dans l'œuvre de Monique Wittig, The Straight Mind (Boston, Beacon Press, 1992), a été publié dans la revue Feminist Issues entre 1980 et 1985.

${ }^{22}$ Notamment à la faveur de la publication par Teresa de Lauretis de Technologies of Gender. Essays on Theory, Film, and Fiction, (Bloomington, Indiana University Press, 1987) et de Gender Trouble. Feminism and the Subversion of Identity par Judith Butler (New York, Routledge, 1990).

${ }^{23}$ Gabriela Mora, «Un diálogo entre feministas hispanoamericanas », Hernán Vidal (ed.), Cultural and Historical Grounding for Hispanic and Luso-Brasilian Feminist Literary Criticism, op. cit., p. 53-57.

${ }^{24}$ Ibid., p. 61-63.
} 
H. : Ese es el problema de algunas explicaciones psicoanalíticas que parecen estáticas e inoperables al situarlas en específicos momentos históricos movidos por fuerzas socio-económicas no contempladas en esos modelos ${ }^{25}$.

On retrouve le même argumentaire dans les années quatre-vingt dix sous la plume de Lucía Guerra Cunningham, dans un article paru dans Feminaria et dont le titre -«Alternative idéologique du féminisme latino-américain $»-$ met en évidence la volonté de différenciation qui anime la critique féministe latino-américaine:

Dentro del contexto periférico (latinoamericano) donde lo europeo es el centro dominante superpuesto, los planteamientos revolucionarios de Luce Irigaray, Julia Kristeva y Hélène Cixous se transforman en puntos de partida de otras espirales engendradas por una asimilación problemática y no lineal del conocimiento feminista contemporáneo. De este modo, los recursos del cuerpo, verdadera matriz ideológica del pensamiento francés y norteamericano, resultan insuficientes y hasta esencialistas y biologizantes en un continente marcado por la represión política y la tortura. [...]. La especificidad de este cuerpo femenino en nuestro continente adquiere rasgos que, lejos de histerizarse, se historizan cuando alojando la fotografía de un hijo desaparecido, asumen la función de un cuerpo político. La maternidad se abre y despliega en una contingencia que, en el caso de las Madres de la Plaza de Mayo, resulta ser el recurso más efectivo en la resistencia política ${ }^{26}$.

La référence aux «Mères de la Place de Mai », qui furent les premières à dénoncer publiquement la politique des disparitions durant la «Guerre Sale » en Argentine, est centrale dans la construction d'une mythologie féministe propre, fondée sur la resémentisation politisante des topiques différentialistes -ici, des rapports entre corps et écriture et de la figure de «La Mère ». Dans le discours de la critique, qui problématise l'inflexion du positionnement féministe hégémonique à l'œuvre dans les ex-colonies du Tiers-Monde, le rapport privilégié de l'écriture féminine, au corps, à la maternité et à la pulsion de vie des féministes françaises est ainsi resignifié dans une économie de la subversion qui cherche à miner les discours autoritaires et leur inscription dans la pulsion de mort.

Le questionnement des deux positionnements qui orienteraient le féminisme international est ainsi informé par la critique du mysticisme déréalisant, de l'idéalisme utopique paralysant ou encore de la dangereuse fragmentation post-moderne du sujet politique qui seraient attachés à ces postures et dont les autrices latino-américaines, immergées dans une réalité politique complexe et travaillant à la création des conditions de possibilité de l'action collective, ne pourraient se satisfaire. Dès lors, la tension entre rejet de l'essentialisme et maintien du féminin comme indice identificatoire, s'actualise dans la revendication d'un positionnement féministe politisé, qui revendique les ressources de l'affirmation identitaire et s'appuierait autant sur les conceptualisations «différentialistes » que «déconstructivistes »-identifiées comme caractérisant les féminismes des centres culturels- qu'il les rejetterait toutes deux.

C'est au final l'«impureté » définitoire des stratégies de positionnement féministes en littérature -situées à l'intersection des logiques croisées du «questionnement des différenciations sexuées hiérarchisantes » et de «la revendication de la différence »- qui se donne à voir dans le trafic de théories auquel se livre la critique féministe latino-américaine et dans le positionnement hybride qui la caractérise. Les historiennes du mouvement féministe en Amérique Latine, à l'image de Francesca Gargallo, insistent ainsi sur la remise en cause de l'alternative entre la posture «différentialiste » et «déconstructiviste » qui serait à l'œuvre dans la critique féministe latino-américaine, mettant en évidence que la recontextualisation et la traduction culturelle des théories empruntées aux centres va déboucher sur la construction d'un positionnement impur, à la croisée du «questionnement des différenciations » et de la « revendication de la différence »:

\footnotetext{
${ }^{25}$ Ibid., p. 65-68.

${ }^{26}$ Lucía Guerra Cunningham, «Alternativas ideológicas del feminismo latinoamericano », Feminaria, año V, n ${ }^{\circ}$ 8, 1992, p. 2.
} 
Las feministas latinoamericanas se vieron obligadas a definir su práctica a partir de los dos modos de ser feministas que se manifestaban en Europa y E.E.U.U., pero lo vivieron en formas particulares ligadas a sus historias nacional y continental, a su ubicación étnica y a su participación política, generando interpretaciones muy particulares, ininteligibles sin un análisis del cómo y desde dónde se ubicaban las feministas frente a la realidad. En el ámbito latinoamericano, la política feminista ha transitado y constantemente transita [...] de la afirmación de una diferencia positiva de las mujeres, con respecto al mundo de los hombres, a la «teoría de géneros $^{27} \gg$.

En ce sens, la conception politico-identitaire du féminin en écriture que développe la critique chilienne Nelly Richard, présentée comme le résultat de « la traduction locale des signes de la pensée féministe internationale ${ }^{28} »$, oscillant entre la convocation du potentiel politique de la revendication identitaire qui fraye avec l'éthique de la subversion kristévienne et la promotion des pratiques de resignification à la Butler, mettant en avant le genre comme variable identitaire construite tout en revalorisant le féminin en écriture, reflète une démarche encore majoritairement partagée par la critique féministe latino-américaine aujourd'hui.

Une réflexion plus approfondie serait à mener afin de déterminer si cette impureté revendiquée -en fonction des contextes historiques (et notamment du tournant des années quatre-vingt dix), des aires culturelles (Cônes Sud, Mexique ou Amérique centrale où se pose différemment l'intersection entre la problématique du genre et de la race) ainsi que des souschamps envisagés (cercle restreint de la littérature d'élite ou dite de «masse », ou encore circuits plus alternatifs, proches des subcultures sexuelles) - tient plus de «l'essentialisme stratégique », autrement dit de l'essentialisation transitoire de l'identité subalterne mise au service de l'intérêt politique que défend Gayatri Spivak par exemple dans un des essais fondateurs de la pensée postcoloniale, «Can the subaltern speak ? ${ }^{29}$ au début des années quatre-vingts ou des plus contemporaines politiques queers des identités post-identitaires. Audelà des disparités qu'une analyse détaillée et comparative porterait assurément au jour, la prise en considération de l'hétéroglossie du discours critique féministe latino-américain en littérature qui fait éclater la polémique aux contours bien tracés entre partisanes et pourfendeuses de l'écriture féminine, nous invite toutefois à envisager que la tension entre «différentialisme » et «questionnement des différenciations » a historiquement été informée par la nécessité de déployer des représentations ambiguës du rapport des femmes à l'écriture, qui permettent de déstabiliser la trame monologique de la «poétique du mâle » et de ses scénarios identitaires, socio-sexuellement rigides. Ce que cette hybridité assumée révèle c'est qu'il n'est peut-être pas pertinent d'envisager en terme d'essentialisme ou de constructivisme des stratégies de résistance littéraire impures, inhéremment ambivalentes, qui -produit de la confrontation à ce que Marta Minow nomme le «dilemme de la différence ${ }^{30} »$ ont irréductiblement articulé la remise en cause des assignations sexuées et la revendication stratégique du féminin comme indice identificatoire. Le trafic de théories à l'œuvre dans les marges exhibe en effet l'ambivalence productive, au principe d'un remaniement complexe des rapports entre création et «différence des sexes», nous forçant à penser que le différentialisme stratégique, à l'honneur dans les années quatre-vingts et quatre-vingt dix, fut en partie précontraint par le caractère schématique et simpliste de la cosmogonie littéraire masculiniste, monologiquement fondée sur la forclusion du féminin et la construction

\footnotetext{
${ }^{27}$ Francesca Gargallo, Ideas feministas latinoamericanas [En ligne], México, Ediciones fem-e-libros, 2004, p. 37-38. [http://creatividadfeminista.org]. Voir également à ce sujet: María Luisa Femenías, Sobre sujeto y género. Lecturas feministas desde Beauvoir a Butler, Buenos Aires, Catálogos, 2000.

${ }^{28}$ Nelly Richard, Masculino/Femenino: prácticas de la diferencia y cultura democrática, Santiago de Chile, Francisco Zegers, 1993, p. 21-22.

${ }^{29}$ Gayatri Spivak, «Can the Subaltern Speak ? », Patrick Williams y Laura Chrisman (eds.), Colonial Discourse and Post-Colonial Theory. A Reader, Hertfordshire, Prentice Hall, 1993.

${ }^{30}$ Martha Minow, «Learning to Live with the Dilemma of Difference: Bilingual and Special Education », Law and Contemporary Problems, vol. 48, n² 2, Part 2, Spring 1985.
} 
naturalisée d'une féminité mythique, incompatible avec la création. Elle éclaire peut-être enfin les contradictions inhérentes aux discours féministes en littérature qui -faisant souvent l'impasse d'une remise en question du schéma élitiste et moderniste de la création littérairese voit contraints de maintenir stratégiquement le féminin afin de composer avec les rapports verrouillés entre genre et Art qui sous-tendent l'institution littéraire. Un autre développement, qui exigerait de revenir plus en détails sur les spécificités de l'actualisation en Amérique Latine des liens entre République des Lettres, vision moderniste de l'artiste et « différence des sexes », dans leurs fondements historiques et théoriques.

\section{Bibliographie}

Butler, Judith, Gender Trouble. Feminism and the Subversion of Identity, New York, Routledge, 1990.

Castillo, Debra, Talking Back. Toward a Latin American Feminist Literary Criticism, Ithaca, Cornell University Press, 1992.

Castro Klarén, Sara «La crítica literaria feminista y la escritora en América Latina », Patricia Elena González y Eliana Ortega (ed.), La sartén por el mango, Río Piedras, Ediciones Huracán, 1985, p. 27-44.

Castro Klarén, Sara (Ed.), Narrativa femenina en América Latina. Prácticas y perspectivas teóricas, Madrid/Frankfurt, Iberomaricana/Vervuert, 2003.

Cixous, Hélène, Le rire de la Méduse et autres ironies, Paris, Galilée, 1975-2010.

Coquillat, Michelle, La poétique du mâle, Paris, Gallimard, 1982.

De Lauretis, Teresa, Technologies of Gender. Essays on Theory, Film, and Fiction, Bloomington, Indiana University Press, 1987.

Delphy, Christine, L'ennemi principal 2/ Penser le genre, Paris, Syllepse, 2001.

Femenías, María Luisa, Sobre sujeto y género. Lecturas feministas desde Beauvoir a Butler, Buenos Aires, Catálogos, 2000.

Francesca Gargallo, Ideas feministas latinoamericanas [En ligne], México, Ediciones fem-elibros, 2004. [http://creatividadfeminista.org].

Gilbert, Sandra M. and Susan Gubar, The Madwoman in the Attic: The woman writer and the nineteenth-century literary imagination, New Haven, Yale University, 1979-1984.

González, Patricia Elena, «Introducción », Patricia Elena González y Eliana Ortega (ed.), La sartén por el mango, Río Piedras, Ediciones Huracán, 1985, p. 13-17.

Guerra Cunningham, Lucía, «Las sombras de la escritura: hacia una teoría de la producción literaria de la mujer latinoamericana », Hernán Vidal (ed.), Cultural and Historical Grounding for Hispanic and Luso-Brasilian Feminist Literary Criticism, Mineapolis, Institute for the Study of Ideologies and Literature, 1989, p. 129-161.

Guerra Cunningham, Lucía, «Silencios, disidencias y claudicaciones: los problemas teóricos de la nueva crítica feminista », Carmen Berenguer, Eugenia Brita, Diamela Eltit, Raquel Olea, 
Eliana Ortega y Nelly Richard (eds.), Escribir en los bordes. Congreso internacional de literatura femenina latinoamericana 1987, Santiago de Chile, Cuarto Propio, 1990, p. 45-51.

Guerra Cunningham, Lucía, "Alternativas ideológicas del feminismo latinoamericano », Feminaria, año V, nº 8, 1992, p. 1-2.

Guerra Cunningham, Lucía, La mujer fragmentada. Historia de un signo, La Habana, Casa de las Américas, 1994.

Guerra Cunningham, Lucía, Mujer y escritura. Fundamentos teóricos de la crítica feminista, Santiago, Cuarto Propio, 2008.

Hooks, Bell, Ain't I a Woman ? Black Women and Feminism, London, Pluto Press, 1981.

Lima Costa, Claudia de, «Repensando el género : tráfico de teorías en las Américas », María Luisa Femenías (comp.), Perfiles del feminismo iberoamericanos, Buenos Aires, Catálogos, 2002, p. 189-214.

Masiello, Francine, El arte de la transición, Buenos Aires, Norma, 2001.

Méndez Rodenas, Adriana, «Tradición y escritura femenina », Carmen Berenguer, Eugenia Brita, Diamela Eltit, Raquel Olea, Eliana Ortega y Nelly Richard (eds.), Escribir en los bordes. Congreso internacional de literatura femenina latinoamericana 1987, Santiago de Chile, Cuarto Propio, 1990, p. 53-64.

Minow, Martha, «Learning to Live with the Dilemma of Difference: Bilingual and Special Education », Law and Contemporary Problems, vol. 48, n 2, Part 2, Spring 1985, p. 157-211.

Mora, Gabriela, «Un diálogo entre feministas hispanoamericanas », Hernán Vidal (ed.), Cultural and Historical Grounding for Hispanic and Luso-Brasilian Feminist Literary Criticism, Mineapolis, Institute for the Study of Ideologies and Literature, 1989, p. 53-77.

Ortega, Eliana, "Y después de todo aquí estamos », Carmen Berenguer, Eugenia Brita, Diamela Eltit, Raquel Olea, Eliana Ortega y Nelly Richard (eds.), Escribir en los bordes. Congreso internacional de literatura femenina latinoamericana 1987, Santiago de Chile, Cuarto Propio, 1990, p. 21-24.

Revue de l'Université d'Ottawa, vol. 50, nº 1, Janvier-Mars 1980.

Richard, Nelly, Masculino/Femenino: prácticas de la diferencia y cultura democrática, Santiago de Chile, Francisco Zegers, 1993.

Richard, Nelly, «Feminismo, experiencia y representación », Revista Iberoamericana, vol. LXII, n 176-177, Julio-Diciembre de 1996, p. 733-744.

Showalter, Elaine, A Literature of their Own, London, Virago, 1977.

Spivak, Gayatri, «Can the Subaltern Speak ? , Patrick Williams y Laura Chrisman (eds.), Colonial Discourse and Post-Colonial Theory. A Reader, Hertfordshire, Prentice Hall, 1993.

Wittig, Monique, The Straight Mind, Boston, Beacon Press, 1992. 